\title{
Motivation of Male Students for Preschool Teacher Profession
}

\author{
Ružica Tokić \\ J. J. Strossmayer University of Osijek, Faculty of Education
}

Received 19 June 2018 • Revised 20 July 2018 • Accepted 28 July 2018

\begin{abstract}
The number of single parent families is on the rise. There is a lack of father figure both in the family and kindergarten where children are exposed to female influence. Eurostat statistical data (2015) show that female teaching staff is dominant in pre-school education with $95 \%$. The number of female preschool teachers in France is 83\%, in Netherlands 86.6\%, in the United Kingdom 90\%. Male preschool teachers are a rare breed in Croatia too, only $2.3 \%$ work in preschool institutions. The aim of the research was to examine motivation of male students for preschool teacher profession. Interviews with all male students enrolled at Undergraduate preschool education in Osijek and Slavonski Brod were conducted. The results showed four clusters of male preschool students' motivation. Students are intrinsically motivated and see this profession as a calling. This topic sheds new light on family pedagogy and opens up insufficiently explored area of research.
\end{abstract}

Keywords: male students, perceptions, preschool teachers.

\section{Introduction}

Caring for children has always been regarded as women's job, but in recent years, scientists started exploring the influence of father and other male figures on children's lives (Yogman \& Garfield, 2016; Carrillo, Bermúdez, Suárez, Gutiérrez \& Delgado, 2016; Leon, Jhe Bai \& Fuller, 2016). New studies show the importance of father involvement in children's lives. Males and females are different and children can only benefit from growing up with two different models of behaviour. In preschool institutions, child should be our focus. Raising the number of preschool teachers who have relevant knowledge, energy, willingness and love for the job, regardless of gender, should also be in the focus of policy makers, universities who educate future experts and the society as a whole.

On one hand, the number of divorces has risen ${ }^{1}$, on the other hand, the trend of decreasing marriage rates is continuing ${ }^{2}$. Also, the number of births outside the marriage is rapidly

${ }^{1}$ In Croatia the number of divorces has risen from 1 per 1000 inhabitants (year 2000) to 1.4 per 1000 inhabitants (year 2013) (Eurostat, 2016).

${ }^{2}$ From 4.9 marriages per 1000 inhabitants in 2000, to 4.5 marriages per 1000 inhabitants in 2013 (Ibid.).

(C) Authors. Terms and conditions of Creative Commons Attribution 4.0 International (CC BY 4.0) apply. Correspondence: Ružica Tokić, Cara Hadrijana 10, 31000 Osijek, CROATIA. E-mail: rtokic@foozos.hr. 
growing in Croatia ${ }^{3}$. This brings us to looser family connections. Also, we are facing different family structures and family dynamics. Children spend long hours in kindergarten and later in school. Parents work hard, sometimes even two jobs in order to make ends meet. Children from an early age attend many extracurricular activities, such as sports or language classes and spend only few hours with their parents (Kralj, 2012; Aman Back, Björkovist, 2004). Raising trend in family research is single motherhood by choice. Reason for this type of motherhood is a combination of desire to become a mother and inability to find a suitable partner (JordanaPröpper, 2013). This has a strong influence on children who are exposed to female influence both at home and in kindergarten.

- Male preschool teachers are a minority and more research needs to be conducted.

- It is important to see what motivates male students to become preschool teachers.

- Four clusters of motivation are constructed after interviewing male students.

The role of men in preschool institutions is not explored enough. Male preschool teachers can bring a lot to a preschool institution if we, as a society, allow them to do their job and not treat them as janitors who are doing all kinds of repairs in kindergarten. They are not here to substitute female preschool teachers, but to create healthy and diverse environment together with their female colleagues. Children can only benefit from diverse activities and personalities of both male and female preschool teachers. Male preschool teachers can serve as a model to young children especially boys. They do a lot of physical activities, unlike female preschool teachers who prefer calm games and lot of rules (Besnard \& Letarte, 2017; Sandberg \& Pramling-Samuelsson, 2005). Previous studies have shown the positive effects of the presence of both parents on early childhood development (Besnard et al., 2017; Lamb, 1996; Mitchell, See, Tarkow, Cabrera, McFadden \& Shannon, 2007; Palm \& Fagan, 2008). In order to provide good development in preschool it is necessary to construct family environment that encompasses both female and male preschool teachers.

\section{Theoretical framework}

Scientific research lacks an up-to-date review of the influence of teacher and preschool teacher gender on children (Sumsion, 2010; Wiest, 2004; Sabbe \& Aelterman, 2007). Differences between boys and girls are seen in early stages of development. Research in the UK, conducted on infants from 9 to 32 months, showed gender differences in toy preferences. Boys choose gender appropriate toys like cars, diggers and balls, while girls choose dolls, pink teddy bears and cooking pots (Todd, Barry \& Thommessen, 2016). This research shows that gender differences are biologically shaped even before the influence of parents, upbringing and society. Furthermore, girls spend more time on group games, routine activities and pictures, where guidance from adults is welcomed. On the other hand, boys spend more time on construction games and outdoor activities that are not pre-planned (Jensen, 1996). Having these differences in mind, it is necessary to include both female and male role models in children's early development. It is also stated in the research that the care provided by men can promote the development of prosocial behaviour in young boys (Jensen, 1996).

Historically, early childhood education has been concerned with the caring for and nurturing of young children and, consequently, continues to be widely regarded as women's work or job (Wiest, 2004; Sumsion, 2010; Mukuna \& Mutsotso, 2011; Jensen, 1996; Simpson, 2005; Stroud, Smith, Ealy, Hurst, 2006; Nordberg, 2010; Sabbe \& Aelterman, 2007; Erden, Ozgun \& Ciftci, 2011). There are a number of reasons for teaching and upbringing being female oriented professions in the history. Women are seen as role models for moral behaviour expressing

3 From 9 live births per 1000 inhabitants in 2000 to 16.1 live births per 1000 inhabitants in 2013 (Ibid.). 
emotional side, unlike men who are seen as strong, independent and fit for higher work positions. During the war periods in history, men had to go on the battlefield and women took their place in school. Women were less paid for the same job which was an important cost saving for schools (Wiest, 2004).

The number of men in early childhood programs has risen over the years. It is due to three related trends (Mukuna et al., 2011: 1876):

(1) the lack of men - usually fathers - in the lives of many young children,

(2) the dearth of men in the early childhood field, and

(3) an increased interest in father involvement in early childhood programs.

On the other hand, Erden et al. (2011) state three main reasons for supporting male teachers. First reason is the absence of father in children's life, next one is males serving as positive role models and final reason is gender equality. Also, Farquhar, Cablk, Buckingham, Butler and Ballantyne (2006) state that children in their formative years spend up to 50 hours a week in childcare environments where they are surrounded by females. Children do not spend enough time with adult males and their contact with positive male role models both in the family and in community is reduced. Moreover, Shaham (1991) identified the following personality factors for the five male preschool teachers he interviewed: individualism, motivation, social awareness, and nonmaterialism (in Wiest, 2004). Numerous research has shown that female preschool teachers tend to use calm activities, more reading and silent play, while male preschool teachers use more physical activities and more turbulent play (Besnard et al., 2017; Sandberg et al., 2005).

Number of authors (Brownhill, 2014; Jones, 2007; Erden et al., 2011) have challenged the question of male early years' teachers. Brownhill (2014) criticized the existence of positive male role models, stating the ambiguity of that phrase. Different men exhibit different individual and professional characteristics, and we can hardly talk about overall population of men serving as positive role models. Some authors are concerned with the safety of children and possible abuse of children by men. Jones (2007) analysed opinions of female teachers on inclusion of men in early years teaching. Female early years' teachers emphasized the possibility of child abuse by men, and would not hire a male teacher not only for the sake of men (to not be exposed to ill treatment) but for their own sake and the sake of other female teachers. Traditional role of females as mothers and protectors is seen here. Results in Erden et al. (2011) research show that society still considers teaching as a female profession.

Sak, Sahin and Sahin (2012) investigated female preschool pre-service teachers' views about male teachers. There were 24 participants and the results have highlighted three main topics: the presence of male preschool teachers, factors affecting male teachers' choice of profession and ways of decreasing negative image of male preschool teachers. Regarding the first topic, most female preschool teachers $(n=21)$ consider men should be involved in preschool teaching. Furthermore, they see men as more creative, better at physical activities and dealing with discipline problems. When it comes to factors affecting male teachers' choice of profession, female preschool teachers state that the main reason is a possibility of advancement to a higher position as administrators or research assistants. But that is also a reason why this profession is considered a female profession. Men usually work as preschool teachers until they find "a path to other work" (Sak et al., 2012: 589), so their aim is career progression. Regarding the third topic, female preschool teachers state that it is necessary to conduct more research related to male preschool teachers in the world and various topics related to preschool education. Moreover, society and parents should be informed via advertisements and TV programs of the role of male teachers in the preschool classroom. The female preschool pre-service teachers stated that male teachers should be involved in preschool teaching because of their professionalism and support for the development of the children's emotional skills. 
Stroud et al. (2006) conducted interviews with 28 male early childhood or elementary education majors. The results have shown that the main impact on choosing this career path had professional educators (teachers, principal) who served as a positive role model to young men. Interviewees also stated that being male is an advantage in this job, but on the other hand, the fact that they are male would set them apart from female colleagues. They consider male and female teachers take up different roles, but they are not related to curriculum or teaching practice but questions of sociological impact, especially in single-parent families. Although the interviewees emphasize the need for more men in this profession, only four students express a desire to stay in classroom teaching. Others reported that they wish to work in administration or college teaching at some future time. It can be concluded that male preschool students from this study are extrinsically motivated for preschool teaching profession.

Erden et al. (2011) conducted a study in Turkey which aim was to understand male preschool teachers' reasons for choosing this profession and their families' and friends' opinions of participants' career choices. The sample was eight volunteer preschool teachers. There were four categories of the research: (1) the reason of choosing pre-school education teaching; (2) families' attitudes towards male preschool education teachers; (3) friends' attitudes towards male pre-school education teachers; and (4) male pre-school teachers' ideal profession. Firstly, the study showed that participants consciously decided to become teachers because of the job guarantee and financial concerns, but if given a chance they would change their profession. Secondly, their families did not support them and they considered it a female job, while friends made fun of them. Lastly, the study has shown that there is still a traditional approach to male preschool teachers in Turkey.

Massari (2014) conducted a study on the sample of 173 students from early childhood education and primary school pedagogy. The aim was to investigate motivation for choosing teaching as a career. The survey with eight questions was used as an instrument. Motivation for teaching was divided into three parts, altruistic, intrinsic and extrinsic reasons. The results have shown that altruistic reasons are on the first place, then intrinsic and lastly extrinsic reasons. Top three reasons for choosing teaching as a career are teaching vocation, love for children and social responsibility for nurturing the young. Furthermore, the results have shown that students from bachelor program are less motivated for teaching than those from the master program. This study included both male and female students with no special mentioning of male students.

Besnard et al. (2017) made most recent research on the sample of 53 teachers $(43 \%$ male) in preschool institutions and 180 children ( $50 \%$ boys). The aim was to investigate social adaptation of children in groups where kindergarten teacher was male and groups where kindergarten teacher was female. Parents assessed children's social adaptation on a given questionnaire, and independent observers assessed teaching practices in usual classroom setting. The results have shown that there are no differences in educational practices between male and female teachers, but the presence of male teachers had an impact on children. "These children were less timid, less anxious, and less withdrawn” (Besnard et al., 2017: 460).

In summary, analyzed research showed that we need more male preschool teachers, but that the notion of preschool teacher profession being female still prevails. From the analysis of the previous research, it can be concluded that there is a lack of research on male preschool students' motivation. Although there is a number of research dealing with topics such as motivation for choosing preschool teaching in general, opinions of female preschool teachers on inclusion of men in childcare institutions, and opinions of male preschool teachers who are already employed, there is not enough research on male students choosing to become preschool teachers. We hope to shed new light on this area of research so needed in contemporary society. 


\section{Method}

\section{1 Research design}

The aim of the study was to explore motivation of male students for preschool teacher profession. Therefore, in this study we conducted interviews with male preschool students from the Faculty of Education in Osijek and Slavonski Brod4, in order to collect needed data.

\section{2 Sample}

First, second and third year male students enrolled at Undergraduate preschool education in Osijek and Slavonski Brod participated in the research. According to Act on Preschool Upbringing and Education (Zakon o predškolskom odgoju i obrazovanju, 2014) in Article 24, paragraph 4, person with undergraduate university degree of appropriate kind can establish employment relationship in kindergarten institution and take care of children from 6 months to school. On the graduate level on the Faculty of Education in Osijek there are no male students, so only undergraduate male students were included in the research. The sample was purposive because the aim of the research was to explore motivation of male preschool students; therefore, all male preschool students from Osijek and Slavonski Brod were included in the research. Percentage of male students in Undergraduate pre-school education studies on the Faculty of Education in Osijek (Chart 1) is 4.14\% (162 female and 7 male students). Number of male students in Slavonski Brod is 3, while the overall number of students there is 159, which means that male students make up only 1,89\% (Chart 2). Overall number of students on the Faculty of Education in Osijek and Slavonski Brod is 328, among which 10 are male and 318 are female students. Percentage of male students on the Faculty of Education in Osijek and Slavonski Brod is 3.05\%. All male students gave their consent to participate in the research. It was expected for the sample to be small, given the fact that male preschool students are still a minority.

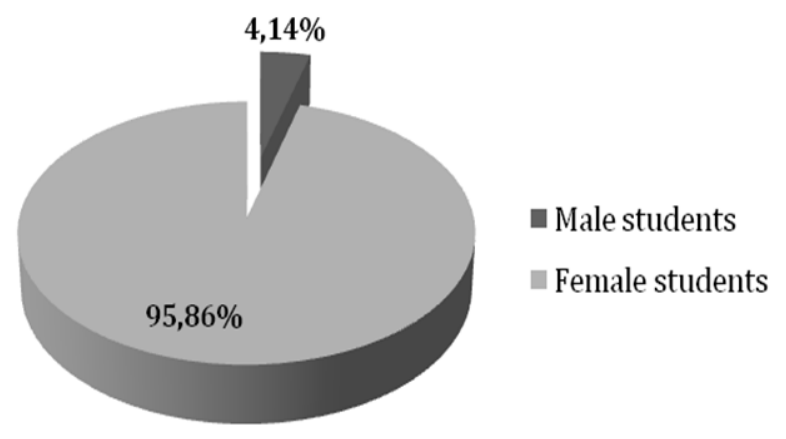

Chart 1. Percentages of female and male students in Undergraduate preschool education studies on the Faculty of Education in Osijek

4 Faculty of Education is situated in Osijek, but it also has a brench in town called Slavonski Brod. 


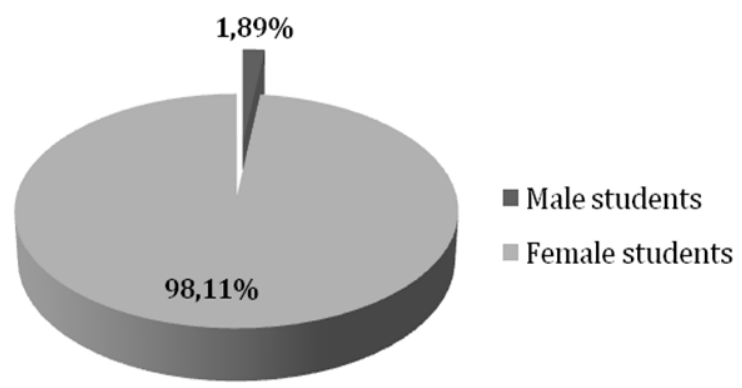

Chart 2. Percentages of female and male students in Undergraduate preschool education studies on the Faculty of Education in Slavonski Brod

\section{3 Data collection}

Data collection was based on qualitative interview method. In-depth interviews with semi-structured questions were conducted. Similar interview was made by Stroud at al. in the United States of America in 2006. The researcher of the present study expanded interview questions and adapted it to Croatian context. Stroud at al. (2006) conducted the interview with elementary education majors and the researcher of the current study made interviews with male preschool students. Stroud at al. (2006) conducted this research 11 years ago, so it was necessary to do another research in this part of the world to see the changes that have occurred during time and possible new trends that have appeared.

All ten male preschool students accepted to participate in the research. The interviewer explained to each participant the aim of the research. Each interview lasted around 20 minutes. During interviews, the researcher used some written questions as a reminder, and the interviews were recorded. All participants were informed that the interview was recorded and they gave their consent. Before data analysis, the interviews were transcribed. After that, the responses were clustered in order to analyse qualitative data and four clusters of male preschool students' motivation were defined.

\section{Results}

After the analysis of in-depth interviews, collected data was grouped in the following four clusters (Chart 3): (1) students' internal and external environment; (2) teaching as a calling; (3) good reputation of the profession; and (4) male preschool teacher as a father figure. These four clusters make up a model for researching motivation of male students for preschool teacher study. All clusters are explained below and students' statements were given in order to provide better understanding of clusters.

\subsection{Students' internal and external environment}

In this cluster, the participants in their responses named environment (both internal as well as external) as an important factor in the choice of preschool profession. Internal environment includes participants' expectations from themselves, but also from their future 
profession. They expect preschool teaching to be dynamic, hard and responsible job (5) and a job that will enable them to develop their competences and knowledge on how to best raise children and work with them (7). Participants consider they are good with children and know how to communicate with them (9) which also motivates them to finish study. Internal environment is the environment on which the participants can directly influence and they can change it with their attitudes and behaviour, while external environment is influenced by society, tradition and current social changes and events.

Students' external environment encompasses family, friends and parents of children they met in kindergartens during their practical work 5 . Students reported that the perception of their family, as well as the parents of children they worked with during their practical work was positive. Their family gave them support in pursuing preschool teaching career. Seven students chose this career by themselves, without the influence of others, while three students reported that others (parents, close relatives and professionals) influenced their choice of profession. Reaction of friends was a bit different because friends were surprised by their choice. One student reported a question that his friend posed on him: Do you need a degree to work with children? After the initial shock, friends accepted their decision which shows that preschool teaching is at first considered a female job. Parents of children that they met during practical work in kindergarten were positively surprised and considered male student as a welcoming change and fresh energy. Male student did not encounter any negative comment from parent nor female preschool teachers. Only two students reported that family members worked in similar profession being teachers, which brings to a conclusion that the influence of parents' education is not crucial in this case, although the support of parents in career choice is important and motivates them even more to work hard and earn a degree. Internal as well as external environment have an important role in motivating male students for preschool profession.

The statements of the students impose these conclusions:

(a) Family is supportive ("My parents were happy when I told them I want to be a preschool teacher"; "They know how good I am with children, so they gave me their support”);

(b) Positive perception of parents in kindergarten on the inclusion of male students ("Parents were intrigued to see me in kindergarten"; "Parent asked if I can stay even longer and come more often");

(c) Making the job dynamic and being responsible ("This job is not easy, you need to understand children and have a lot of energy"; "I would like to bring more TPR activities for the children and more outdoor activities or playing a guitar");

(d) Making friends with children ("I love working with children and I think that I am good with children").

\subsection{Teaching as a calling}

Six out of ten students reported that this was not their first choice of profession. They studied on different faculties, but did not find themselves in these professions. They wanted something more, so after a year or two of studying, they decided to drop out and enroll at the Faculty of Education to become preschool teachers. Seven of the interviewed students said that they enrolled at this Faculty so they could work with children and help them in developing their potentials.

When asked why being a preschool teacher is a desirable profession for men, seven students out of ten responded that it is not a profession or a job, it is a calling. They see preschool

\footnotetext{
${ }^{5}$ Students are obliged to spend a certain amount of time in kindergarten on each year of study to do practical tasks.
} 
teaching as a way of influencing children's lives and helping them grow. Children are different and look for a different approach. Noticing and reacting to children's needs without them being able to tell, is something that cannot be learnt, but a competence you needs to have within you. Moreover, some of them named the possibility of being creative (5) and gaining experience for future upbringing of their own children (4) as a benefits. Students emphasized that this profession is not for everyone, but only for those who are imaginative and able to put children's needs before their own.

The most important statements for this cluster are the following:

(a) "I would not like everyone to become a preschool teacher";

(b) "It is a calling and if you do not feel good working with children, you should not do it";

(c) "This is a job for those who fantasize and dream, who are imaginative and creative, because children's lives are in stake".

\subsection{Positive reputation of the profession}

Male students think that the public is aware of the importance of their profession, because children are the most valuable asset to every parent and parents leave the care for their children in the hands of preschool teachers with outmost trust. They also emphasise that the public does not appreciate enough the work they do. Caring for and educating young children who come from different family backgrounds with different habits is not an easy job. Also, kindergartens in Croatia are crowded. In some kindergartens we have around 20-25 children in a group and just two preschool teachers. Furthermore, seven students said that the term "auntie" should not be used at all. Participants state that they are not nannies, because they care not only for children's upbringing but also for their education and development. Besides, the term "educator" or "teacher" is more appropriate than the term auntie, because then the public would connect this profession with both male and female sex.

Moreover, different workshops could be conducted to show the efficiency of male teachers (7), so that the perception of preschool teaching as a female profession would vanish from the public sphere. Media and scientific research should point out the lack of male preschool teachers (6). Also, positive examples of successful male preschool teachers should be given (5).

Most frequent statements from this cluster are the following:

(a) "It is necessary to inform the public about the importance of male preschool teachers through different workshops";

(b) "Male students could be very good teachers";

(c) "Positive examples of successful male preschool teachers should be presented to the public".

\subsection{Male preschool teacher as a father figure}

Participants find motivation for this profession in the fact that there are not enough male preschool teachers in the kindergarten (10) and that male and female preschool teachers give the right picture of a family (male and female preschool teachers as model of mother and father). They also consider that they can bring fresh energy to kindergarten (8) and that they have more authority (7) than female preschool teachers do. This corresponds to the results of previous research (Besnard et al., 2017; Sandberg et al., 2005; Jensen, 1996). 
Male students expect themselves to act like a father figure (8), and develop in children a sense of good as well as a positive stand towards life and the world around them (6). Male students point out the problems of family pedagogy and modern families, like alienation or using different media resources instead of real conversation and direct communication. Furthermore, high divorce rates call for more men in preschool environment, since male preschool teachers are for some children the only model of male behaviour that they are exposed to. Male students understand that fact as a challenge they are willing to take.

The most important statements for this cluster are the following:

(a) "Men are more authoritative, we use different tone of voice, and different approach to discipline problems";

(b) "I want to create family atmosphere in the kindergarten, so I have a role of the father to fill";

(c) "Men have different approach to upbringing than women";

(d) "We bring more energy to the kindergarten, more sports activities, TPR, and field trips. Movement is extremely important";

(e) "In times of high divorce rates and raising number of single mothers, there is a need for male preschool teachers".

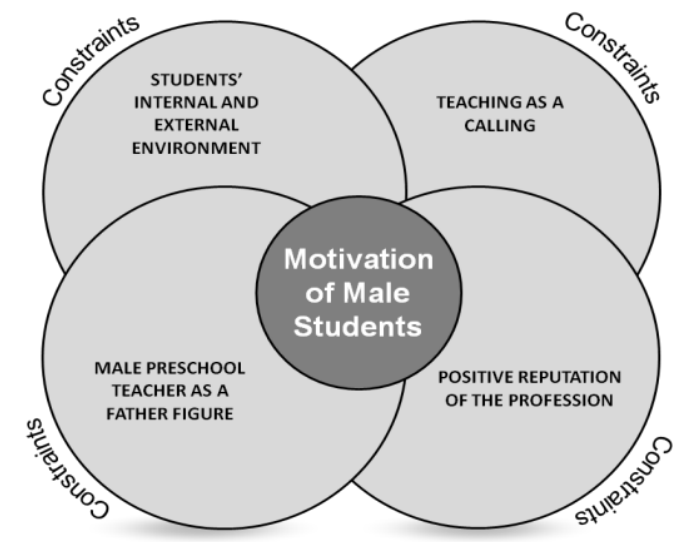

Chart 3. Model of motivation of male preschool students (source: author's research)

\section{Discussion}

The aim of the research was to examine motivation of male students for preschool teacher profession that is still considered as a female profession. After the conducted interviews with ten male students of Undergraduate preschool education at the Faculty of Education in Osijek and Slavonski Brod, four clusters emerged which made a model for researching motivation of male students. This model shows the following four motivation factors: (1) students' internal and external environment; (2) teaching as a calling; (3) positive reputation of the profession; and (4) male preschool teacher as a father figure.

Male students' internal environment is what made them choose this profession in the first place. It encompasses their expectations and beliefs about the profession but also the notion that they have what it takes to be a good preschool teacher. Students' external environment is not something that they can influence on but it is rather concerned with the opinions of close people who have an influence on male students, like family and friends. The important thing for male students' motivation is also the acceptance of kindergarten children's parents, since they are the most important in the lives of children they teach. Mutual acceptance, respect and cooperation is 
crucial, especially for those male students who see preschool teaching as a calling. They are not here just to earn their living, but to get to know the children and influence their development in best way possible. Students are aware that teaching is not a highly esteemed profession, but they emphasise that it has a positive reputation. They see their biggest potential in the possibility to act like a father figure, or as a male figure. Higher divorce rates and single motherhood call for more male preschool teachers who would bring new perspectives and energy to kindergarten.

The results have shown that male students are intrinsically motivated for preschool teacher profession. Six students reported that this was not their first choice, because, like most men, they did not consider it to be a male profession. After enrolment and their first contact with children, they realized how suitable this was for them. Moreover, students gave some good remarks on how to motivate other men who are thinking of becoming preschool teachers. However, they are cautiously saying that it should not be imposed on others, because men should be motivated from the inside.

Although all students responded that they did not experience any obstacles while being in kindergarten, they named a few things that could be considered as an obstacle in their future work. Two of the students mentioned lower social and emotional intelligence in men in comparison to women and two stated negative connotations of men working with small children. One student mentioned male disorganization and seeing a male preschool teacher as a janitor who does all kinds of repairs. Men are seen as stronger sex who can help out with heavy lifting. For two students, the age of the children could be an obstacle because they prefer working with older children. The rest of the students (8) have no problem working with younger children and even in nursery. Above mentioned results are low and did not enter the clusters but they are important and should be discussed. Male students want to be treated the same as their female colleagues, because they are capable of working with children and working good.

If we compare the results of the current research with the results of other researchers, we can conclude that students in Osijek and Slavonski Brod want to stay in the profession, while the research findings of other authors (Stroud at al., 2006; Sak et al., 2012; Erden at al., 2011) state that students would like to change their profession as soon as possible and work on a higher position. This shows that these students, unlike the students from the present study, are extrinsically motivated. Furthermore, in Erden et al. (2011) research male students did not have the support of family and friends, while the results of the present study show good support of family and friends and even children's parents in the kindergarten. All of the interviewed students stated that preschool teacher profession has a positive reputation, but it is not paid enough. Reputation is far from the one it deserves, because it is considered a female job, and usually female professions are paid poorly and not valued enough in the society. The students emphasise the influence of tradition and division of professions on male and female. They are bothered with the term "auntie" so frequently used in our society.

The results of this study show how, even though still traditional, Croatia as a country opens up to new possibilities by slowly embracing male preschool teachers. Number of preschool students is slowly raising, but they need the support of the whole society. More practical visits to kindergartens should be made during high school, the term "auntie" should be terminated and more research should be done. The results can also help in bringing a positive social change concerning the view of male preschool teachers. Model of male preschool students' motivation with corresponding four categories could be used in future research to test the model in other parts of Croatia or even in other countries. Furthermore, interviews could be made with male preschool teachers who are employed to see how their motivation increased or decreased after a certain amount of years working with children. Also, the next logical step would be a longitudinal study with these students measuring their motivation after the first and third year of work. 


\section{Conclusion}

This area of research is becoming more popular and needed due to recent changes in family pedagogy. The research was conducted with all male students who study preschool education on the J. J. Strossmayer University of Osijek through interviews. Therefore, all the information was gathered directly from the respondents. Precisely a small number of these students allowed direct examination of all of them and thus contributed to the value of this research. Through the interviews, fundamental knowledge of their motivation to choose this profession was gathered. Research results point to the importance of systematic research in this area so that educational models can track changes in today's families.

Few studies have examined motivation of male students for preschool teaching. Current study provides a model for investigating male students' motivation. The model consists of four categories: (1) students' internal and external environment, (2) teaching as a calling, (3) good reputation of the profession, and (4) male preschool teacher as a father figure. Male students are intrinsically motivated for preschool teacher profession. That is why we need more men, to bring novelty in kindergarten and equally participate in upbringing and educating children. Getting more men into preschool teaching is still a long process that cannot happen overnight. Men being part of preschool teacher profession is still unrecognised field of study in Croatia. However, it is important to start the process. This study sheds a new light on this area of research.

\section{Acknowledgements}

This research did not receive any specific grant from funding agencies in the public commercial, or not-for-profit sectors.

The authors declare no competing interests.

\section{References}

Aman Back, S., \& Björkovist, K. (2004). Parents' assessment of how much time they spent with their children at different ages. Psychological Reports, 94, 1025-1030.

Besnard, T., \& Letarte, M. (2017) Effect of male and female early childhood education teacher's educational practices on children's social adaptation. Journal of Research in Childhood Education, 31(3), 453-464.

Brownhill, S. (2014). "Build me a male role model!" A critical exploration of the perceived qualities/characteristics of men in the early years (0-8) in England. Gender and Education, 26(3), 246-261.

Carrillo, S., Bermúdez, M., Suárez, L., Gutiérrez, M. C., \& Delgado, X. (2016). Father's perceptions of their role and involvement in the family: a qualitative study in a Colombian sample. Revista Costarricense de Psicologia, 35(2), 101-118.

Erden, S., Ozgun, O., \& Ciftci, M. (2011). "I am a man, but I am a pre-school education teacher": Self- and social-perception of male pre-school teachers. Procedia Social and Behavioral Sciences, 15, 3199-3204.

Eurostat (2016). Marriage and divorce statistics. Retrieved 10 April 2018 from: http://ec.europa.eu/eurostat/statisticsexplained/index.php/Marriage and divorce statistic s\#Fewer marriages.2C more divorces. 
Farquhar, S., Cablk, L., Buckingham, A., Butler, D., \& Ballantyne, R. (2006). Men at work: Sexism in early childhood education. Childforum Research Network. Retrieved 15 April 2018 from: http://www.childforum.com.

Jensen, J. (1996). Men as workers in childcare service. A discussion paper. European Commission Network on Childcare, London (England). Retrieved 15 May 2018 from: https://eric.ed.gov/?id=ED403080.

Jones, D. (2007). High risk men: male teachers and sexuality in early years contexts. International Journal of Adolescence and Youth, 13(4), 239-255.

Jordana-Pröpper, O. (2013). An anthropological approach to voluntarily single motherhood in Barcelona. Journal of Comparative Research in Anthropology and Sociology, 4(1), 41-61.

Kralj, D. (2012). Primjeren izbor slobodnih aktivnosti za dijete. http://www.poliklinikadjeca.hr/aktualno/teme/izbor-slobodnih-aktivnosti-za-dijete/. Accessed 29 May 2018.

Lamb, M. E. (1996). The development of father-infant relationships. In: M. E. Lamb (Ed.), The role of the father in child development (pp. 104-120). New York: John Wiley and Sons.

Leon, S. C., Jhe Bai, G., \& Fuller, A. K. (2016). Father involvement in child welfare: Associations with changes in externalizing behavior. Child Abuse \& Neglect, 55, 73-80.

Massari, G. (2014). Motivation for Teaching Career of Students from Early Childhood Education and Primary School Pedagogy. Acta Didactica Napocensia, 7, 4, 1-6.

Mitchell, S. J., See, H. M., Tarkow, A. K. H., Cabrera, N., McFadden, K. E., \& Shannon, J. D. (2007). Conducting studies with fathers: Challenges and opportunities. Applied Development Science, 11(4), 239-244.

Mukuna, T., \& Mutsotso, S. (2011). Gender inequalities in early childhood development education teaching profession in Kenya. Educational Research, 2(13), 1876-1885.

Nordberg, M. (2010). Constructing masculinity in women's worlds: Men working as pre-school teachers and hairdressers. NORA - Nordic Journal of Feminist and Gender Research, 1O(1), 26-37.

Palm, G., \& Fagan, J. (2008). Father involvement in early childhood programs: Review of the literature. Early Child Development and Care, 178(7-8), 745-759.

Sabbe, E., \& Aelterman, A. (2007). Gender in teaching: A literature review. Teachers and Teaching, 13(5), 521-538.

Sak, R., Sahin, I., \& Sahin, B. (2012). Views of female preschool pre-service teachers about male teaching colleagues. Procedia - Social and Behavioral Sciences, 47, 586-593.

Sandberg, A., \& Pramling-Samuelsson, I. (2005). An interview study of gender difference in preschool teachers' attitudes toward children's play. Early Childhood Education Journal, 32(5), 296305.

Simpson, R. (2005). Men in non-traditional occupations: Career entry, career orientation and experience of role strain. Uxbridge UK: School of Business and Management, Brunel University.

Stroud, J., Smith, L., Ealy, L., \& Hurst, R. (2006). Choosing to teach: Perceptions of male pre-service teachers in early childhood and elementary education. Early Child Development and Care, 163(1), 49-60.

Sumsion, J. (2010). Negotiating otherness: A male early childhood educator's gender positioning. International Journal of Early Years Education, 8(2), 129-140.

Todd, B., Barry, J., \& Thommessen, S. (2016). Preferences for 'gender-typed' toys in boys and girls aged 9 to 32 months. Infant and Child Development, 1-14.

Wiest, L. (2004). The current status of male teachers of young children. The Educational Forum, 68(1), 6270. 
Yogman, M., \& Garfield, C. (2016). Fathers' roles in the care and development of their children: The role of pediatricians. Pediatrics, 138(1), 1-15.

Zakon o predškolskom odgoju i obrazovanju (2014). https://www.zakon.hr/z/492/Zakon-0pred\%C5\%A1kolskom-odgoju-i-obrazovanju Accessed 1 June 2018. 
R. Tokić - Motivation of Male Students for Preschool Teacher Profession

C O A $\mathrm{s}$ 